\title{
Avaliação do cultivo heterotrófico de Phormidium sp. utilizando sacarose como fonte de carbono orgânico.
}

Stefania F. Siqueira ${ }^{1}$; Tatiele C. do Nascimento ${ }^{1}$; Leila Q. Zepka ${ }^{1}$; Maria Isabel Queiroz ${ }^{2}$; Eduardo Jacob-Lopes ${ }^{1}$;

${ }^{1}$ Universidade Federal de Santa Maria, Depto. de Tecnologia e Ciência de Alimentos, Av. Roraima, 1000, CEP 97105-900, Santa Maria, Rio Grande do Sul, Brasil - E-mail: jacoblopes@pq.cnpq.br

${ }^{2}$ Universidade Federal do Rio Grande (Furg) Departamento de Química; CEP 96201-900 - Rio Grande (RS), Brasil.

RESUMO - O estudo teve como objetivo avaliar o cultivo heterotrófico de Phormidium $s p$. utilizando sacarose como fonte de carbono orgânico em diferentes razões carbononitrogênio. As razões carbono-nitrogênio estudadas foram de 20,30 e 40 . Os experimentos foram conduzidos em um biorreator de coluna de bolhas, em condições experimentais de concentração inicial de inóculo de $100 \mathrm{mg} / \mathrm{L} ; \mathrm{pH}$ de 7,6; temperatura de $30^{\circ} \mathrm{C}$; aeração constante de $1 \mathrm{VVM}$ (volume de ar por volume de meio por minuto) e ausência de luminosidade. Os resultados obtidos indicaram que a maior produtividade de biomassa (40,76 mg/L.h) e a maior produtividade lipídica $(8,47 \mathrm{mg} / \mathrm{L} . \mathrm{h})$ foram alcançadas a partir da razão carbono-nitrogênio de 40.

\section{INTRODUÇÃO}

Cianobactérias são microrganismos procariontes largamente distribuídos na natureza que possuem a capacidade de crescer no escuro, utilizando substratos orgânicos (Sánchez-Luna et al. 2004). Várias espécies de microalgas, têm sido consideradas organismos promissores para várias aplicações biotecnológicas e são alvo de estudos devido ao seu potencial para diversas formas renováveis de compostos químicos úteis, tanto para alimentação humana como animal, além de produtos farmacêuticos, biofertilizantes, entre outras aplicações (Molina et al. 2002).

O efeito de mudanças nas condições ambientais em culturas de muitas espécies de cianobactérias tem sido estudados para um melhor entendimento da sua fisiologia e para responder questões específicas no que se refere ao crescimento de culturas. A ação de alguns nutrientes, como carbono e nitrogênio, permite obter resultados sobre algumas tendências gerais de culturas em batelada (Lourenço et al. 1997).

Segundo Pereira et al. (2012) a procura por fontes alternativas e economicamente viáveis de substratos tem sido o principal foco de pesquisadores que buscam vencer as barreiras econômicas e ambientais para o setor de energias renováveis. Assim, a fonte ideal para a produção de biocombustível depende principalmente da sua disponibilidade e do seu custo. A sacarose constitui até $60 \%$ da biomassa seca de algumas plantas como a beterraba e a cana de açúcar, pode ser uma alternativa como fonte de carbono para o 
cultivo de microalgas em processos de produção de óleos unicelulares (Olguín et al. 2008).

\section{OBJETIVO}

O estudo teve como objetivo avaliar a aplicação da sacarose como fonte de carbono orgânico em cultivos heterotróficos de phormidium $s p$.

\section{METODOLOGIA}

\subsection{Microrganismo e condições de cultivo}

A cianobactéria utilizada foi a Phormidium sp., isolada do Deserto Cuatro Cienegas no México $\left(26^{\circ} 59^{\prime} \mathrm{N} 102^{\circ} 03 \mathrm{~W}\right)$. Após purificação, as culturas estoque foram mantidas em tubos de ensaio com meio sintético BGN (Rippka et al., 1979) solidificado com agar-agar. As condições de manutenção usadas foram $30^{\circ} \mathrm{C}$ e intensidade luminosa constante de 1 klux e aeração constante.

\subsection{Meio de cultura}

Utilizou-se o meio sintético BGN (Rippka et al., 1979) para diluição e suplementação de nutrientes inorgânicos. A composição química do $\mathrm{BGN}$ é: $\mathrm{K}_{2} \mathrm{HPO}_{4}$ $\left(0,03 \mathrm{~g} \cdot \mathrm{L}^{-1}\right), \mathrm{MgSO}_{4} \quad\left(0,075 \mathrm{~g} \cdot \mathrm{L}^{-1}\right), \mathrm{CaCl}_{2} \cdot 2 \mathrm{H}_{2} \mathrm{O}\left(0,036 \mathrm{~g} \cdot \mathrm{L}^{-1}\right)$, citrato de amônio e ferro $\left(0,0006 \mathrm{~g} \cdot \mathrm{L}^{-1}\right), \mathrm{Na}_{2}$ EDTA $\left(0,001 \mathrm{~g} \cdot \mathrm{L}^{-1}\right), \mathrm{NaCl}\left(0,00072 \mathrm{~g} \cdot \mathrm{L}^{-1}\right), \mathrm{NaNO}_{3}\left(0,015 \mathrm{~g} \cdot \mathrm{L}^{-1}\right)$, ácido cítrico $\left(0,0006 \mathrm{~g} . \mathrm{L}^{-1}\right), \quad \mathrm{Na}_{2} \mathrm{CO}_{3} \quad\left(1,5 \mathrm{~g} \cdot \mathrm{L}^{-1}\right)$, metais traços: ${ }_{\mathrm{H}_{3} \mathrm{BO}_{3}} \quad\left(0,0028 \mathrm{~g} \cdot \mathrm{L}^{-1}\right)$, $\mathrm{MnCl}_{2} .4 \mathrm{H}_{2} \mathrm{O}\left(0,0018 \mathrm{~g} . \mathrm{L}^{-1}\right), \mathrm{ZnSO}_{4} .7 \mathrm{H}_{2} \mathrm{O}\left(0,00022 \mathrm{~g} \cdot \mathrm{L}^{-1}\right), \mathrm{Na}_{2} \mathrm{MoO}_{4} \cdot 2 \mathrm{H}_{2} \mathrm{O}\left(0,00039 \mathrm{~g} . \mathrm{L}^{-}\right.$ $\left.{ }^{1}\right), \mathrm{CoSO}_{4} \cdot 6 \mathrm{H}_{2} \mathrm{O}\left(0,00004 \mathrm{~g} \cdot \mathrm{L}^{-1}\right)$. O carboidrato empregado nos cultivos foi a sacarose, na concentração de 26g/L, 40g/L e 51g/L, para as razões carbono-nitrogênio de 20, 30 e 40 respectivamente.

\subsection{Biorreator e condições experimentais}

Os experimentos foram realizados em biorreator de coluna de bolhas construído de vidro borossilicato, com um diâmetro externo de $12,5 \mathrm{~cm}$ e uma altura de $16 \mathrm{~cm}$, resultando numa razão altura/diâmetro (L/D) igual a 1,28, com um volume total de trabalho de 2,0L. O sistema de dispersão de ar consiste em um difusor de 2,5cm de diâmetro localizado no interior do frasco. A vazão de ar foi controlada por rotâmetros (precisão $\pm 5 \%$ ), a entrada de oxigênio e a saída dos gases foram filtradas através de unidades filtrantes Millex-FG ${ }^{\circledR}$, em polipropileno com membrana fluoropore de $0,22 \mu \mathrm{m}$ 
de diâmetro e 50mm de diâmetro total. As condições de cultivos foram: concentração celular inicial de $100 \mathrm{mg} / \mathrm{L}$; pH de 7,8; temperatura de $30^{\circ} \mathrm{C}$; aeração de $1 \mathrm{VVM}$ (volume de ar por volume de meio por minuto) e ausência de luminosidade.

\subsection{Amostragem e análise dos parâmetros cinéticos}

As amostragens foram realizadas de forma asséptica a cada 24 horas durante a fase de crescimento do microrganismo. A concentração celular e a quantidade de lipídeos foram determinadas através de gravimetria. Os dados de biomassa foram utilizados na obtenção da velocidade máxima específica de crescimento $\left(\ln \left(X / X_{0}\right)=\mu_{\max } \cdot t\right)$, onde $X$ é a concentração celular final (mg/L), $X_{0}$ é a concentração celular inicial $(\mathrm{mg} / \mathrm{L}), \mu_{\max }$ é a velocidade máxima específica de crescimento $\left(\mathrm{h}^{-1}\right)$ e t é o tempo de residência $(\mathrm{h})$, no cálculo da produtividade de biomassa $\left(\mathrm{P}_{\mathrm{X}}=\mu . \mathrm{X}\right)$. A quantidade lipídica de biomassa foi utilizada na obtenção de sua produtividade $\left(\mathrm{P}_{\mathrm{L}}=\mathrm{P}_{\mathrm{x}}\right.$.Lipídeos $)$. Os experimentos foram realizados em duplicata e os dados cinéticos referem-se à média de quatro repetições.

\subsection{Análise lipídica}

\subsubsection{Secagem da biomassa}

A biomassa foi separada do meio de cultivo por decantação, seguido de centrifugação. Em seguida, a pasta obtida foi seca em estufa com circulação de ar a temperatura a $60^{\circ} \mathrm{C}$.

\subsubsection{Extração e determinação quantitativa do lipídeo}

Para a extração de lipídeos totais da biomassa, foi utilizado o método de Bligh e Dyer (1959) modificado, levando-se em conta as proporções entre os solventes metanol e clorofórmio, e água destilada (2:1:0.8). Os lipídios da biomassa seca foram extraídos após secagem e trituração em almofariz. A quantidade de lipídeos foi determinada por gravimetria a partir do extrato total de clorofórmio, evaporando-se o solvente em atmosfera de nitrogênio e posteriormente seco em estufa e submetido a peso constante.

\section{RESULTADOS E DISCUSSÃO}

A avaliação de fontes de carbono no cultivo de cianobactérias é um passo fundamental na consolidação de rotas de produção de biomassa a lipídeos a partir de sistemas heterotróficos. Neste sentido, a Tabela 1 apresenta os parâmetros cinéticos 
empregando sacarose em diferentes razões carbono-nitrogênio no cultivo heterotrófico da microalga Phormidium sp.

\begin{tabular}{lccccc}
\hline Sacarose & $\begin{array}{c}\mu \text { máx } \\
\left(\mathrm{h}^{-1}\right)\end{array}$ & $\begin{array}{c}\text { Xmáx } \\
(\mathrm{mg} / \mathrm{L})\end{array}$ & $\begin{array}{c}\text { Px } \\
(\mathrm{mg} / \mathrm{L} . \mathrm{h})\end{array}$ & $\begin{array}{c}\text { Lipídeos } \\
(\%)\end{array}$ & $\begin{array}{c}\mathrm{P}_{\mathrm{L}} \\
(\mathrm{mg} / \mathrm{L} . \mathrm{h})\end{array}$ \\
\hline C/N 20 & 0,0135 & 2775 & 14,73 & 8,9 & 1,32 \\
C/N 30 & 0,0203 & 5260 & 34,44 & 18,64 & 6,41 \\
C/N 40 & 0,0214 & 6170 & 40,76 & 20,78 & 8,47
\end{tabular}

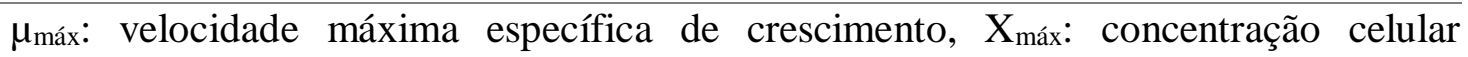
máxima, $\mathrm{P}_{\mathrm{x}}$ : produtividade de biomassa; $\mathrm{P}_{\mathrm{L}}$ : produtividade lipídica.

A maior velocidade máxima específica de crescimento foi alcançada no cultivos com razão carbono-nitrogênio de $40\left(0,0214\right.$ h-1 $\left.^{1}\right)$, seguida da razão carbono-nitrogênio de 30 com $\left(0,0203 h^{-1}\right)$. As máximas concentrações celulares e produtividades em biomassa foram de $6170 \mathrm{mg} / \mathrm{L}$ e $40,76 \mathrm{mg} / \mathrm{L} . \mathrm{h}$, respectivamente, para a razão carbononitrogênio de 40.

Segundo Francisco et al. (2013) dissacarídeos como sacarose são substratos oxidáveis, que servem de reservas energéticas para manter o nível de ATP na célula, no processo de acoplamento da cadeia respiratória aeróbica. Neste sentido, a célula é capaz de utilizar este substrato, adaptando-o para o crescimento heterotrófico de microalgas.

Em termos de produtividade lipídica, valores máximos de $8,47 \mathrm{mg} / \mathrm{L} . \mathrm{h}$ foram obtidos para razão carbono-nitrogênio de 40, refletindo o equilíbrio entre o teor lipídico e a produtividade em biomassa. Cheng et al. (2009), investigaram o efeito de sacarose como fonte de carbono na produção de lipídios de microalgas heterotróficas, Chlorella protothecoides, verificando que o conteúdo lipídico empregando este dissacarídeo como fonte de carbono foi positivo para a produção de óleo de microalgas heterotróficas.

Griffiths et al. (2009) relatam que quando se pretende fazer uma seleção racional de microalgas para a produção de lipídeos unicelulares dois parâmetros como taxa de crescimento e conteúdo lipídico são essenciais, uma vez que este é um produto unicelular, é prioritário o equilíbrio entre estes dois parâmetros do processo visando maximizar as taxas de produção.

\section{CONCLUSÃO}

O cultivo heterotrófico de microalga phormidium $s p$. utilizando sacarose como fonte de carbono, apresentou melhor eficiência em razão carbono-nitrogênio de 40 nas 
condições empregadas, resultando a melhor concentração celular máxima, produtividade de biomassa, conteúdo lipídico e produtividade lipídica, de 6170mg/L, 40,76mg/L.h, 20,78\% e 8,47mg/L.h, respectivamente.

\section{REFERÊNCIAS}

SÁNCHEZ-LUNA, L. D. et al. Continuous and pulse feedings of urea as a nitrogen source in fed-batch cultivation of Spirulina platensis. Aquacultural Engineering, v. 31, n. 3-4, p. 237-245, 2004.

MOLINA GRIMA, E. et al. Recovery of microalgal biomass and metabolites: process option and economics. Biotechnology Advances, v. 20, p. 491-515, 2002.

LOURENÇO, S. O. et al. Changes in Biochemical profile of Tetraselmis gracilis I. Compostion of two culture media. Aquacult, v. 148, n. 2-3, p. 153-168, 1997.

PEREIRA, C.M.P.; HOBUSS, C.B.; MACIEL, J.V.; FERREIRA, L.R.; DEL PINO F.B.; MESKO, M.F.; JACOB-LOPES.; NETO, P.C. Biodisel renovável derivado de microalgas: avanços e perspectivas tecnológicas, v 35, p. 2013-2018, 2012.

OLGuín, E. J., G. SÁNCHEZ-GALVÁN, et al. (2008). "Constructed wetland mesocosms for the treatment of diluted sugarcane molasses stillage from ethanol production using Pontederia sagittata." Water Res 42(14): 3659-3666.

RIPPKA, R.; DERUELES, J.; WATERBURY, J. B.; HERDMAN, M.; STANIER, R. Y. Generic assignments strain histories and properties of pure cultures of cyanobacteria. Journal General Microbiololy, n.111, p.1-61, 1979.

FRANCISCO,E.C.; FRANCO,T.T.; WAGNER,R.; JACOB-LOPES E., Assessment of different carbohydrates as exogenous carbon source in cultivation of cyanobacteria. Bioprocess Biosyst Eng, 2013.

CHENG, Y.; LU, Y.; GAO, C.; WU, Q. Algae-based biodiesel production and optimization using sugar cane as the feedstock. Energy Fuels 2009;23:4166-73.

GRIFFITHS, M.J.; HARRISON, S.T.L., Lipid productivity as a key characteristic for choosing algal species for , 2009 